\title{
Muscle-Organ Crosstalk: Focus on Immunometabolism
}

\author{
Marie Lund Bay and Bente Klarlund Pedersen* \\ Centre of Inflammation and Metabolism/Centre for Physical Activity Research (CIM/CFAS), Rigshospitalet, University \\ of Copenhagen, Copenhagen, Denmark
}

Skeletal muscle secretes several hundred myokines that facilitate communication from muscle to other organs, such as, adipose tissue, pancreas, liver, gut, and brain. The biological roles of myokines include effects on e.g., memory and learning, as well as glucose and lipid metabolism. The present minireview focuses on recent developments showing that exercise-induced myokines are involved in immunometabolism of importance for the control of e.g., tumor growth and chronic inflammation. In this review, immunometabolism is discussed as the non-immune related pathologies leading to an immune response and some degree of inflammation, which promotes metabolic abnormalities.

\section{OPEN ACCESS}

Edited by:

Miguel Luiz Batista Júnior, University of Mogi das Cruzes, Brazil

Reviewed by: Jörn Rittweger, German Aerospace Center, Helmholtz Association of German Research Centers (HZ), Germany

Han-Zhong Feng,

Wayne State University School of Medicine, United States José Cesar Rosa Neto,

University of São Paulo, Brazil

*Correspondence:

Bente Klarlund Pedersen bente.klarlund.pedersen@regionh.dk

Specialty section: This article was submitted to

Striated Muscle Physiology, a section of the journal Frontiers in Physiology

Received: 30 May 2020

Accepted: 19 August 2020 Published: 09 September 2020

Citation: Bay ML and Pedersen BK (2020) Muscle-Organ Crosstalk: Focus on Immunometabolism.

Front. Physiol. 11:567881. doi: 10.3389/fphys.2020.567881
Keywords: metabolism, cytokines, exercise, physical activity, diabetes, cancer

\section{INTRODUCTION}

The term "immunometabolism" was introduced as the interplay between metabolic and immunologic processes (Mathis and Shoelson, 2011). Immunometabolism refers to two concepts. One is how leukocyte and lymphocyte function is regulated by their internal metabolism. The other is how pathologies considered to be non-immune - such as obesity - result in an activation of the immune system, which promotes metabolic abnormalities increasing the risk of type 2 diabetes, cardiovascular diseases and cancer (Mathis and Shoelson, 2011). In this review, the main focus is on the latter understanding of the immunometabolism concept, and on how muscle activation through exercise can counteract some of the inflammatory processes related to these diseases.

Myokines are involved in mediating the multiple physiological, metabolic and immunological effects of physical activity (Pedersen et al., 2003a; Pedersen and Febbraio, 2012).

A single bout of exercise provokes an increase in systemic levels of IL-6 (Pedersen, 2013). In relation to exercise, IL-6 is released as a myokine from muscle into the circulation, and IL-6 plasma levels increase exponentially with exercise duration. Recent findings consolidate the pleiotropic nature of IL-6 and demonstrate a physiological role of this myokine in regulating clinically relevant parameters related to energy homeostasis and immune cell regulation in cancer (Severinsen and Pedersen, 2020).

Following the identification of muscle-derived IL-6, it has become evident that skeletal muscle cells are able to secrete more than 650 myokines (Khan and Ghafoor, 2019). The role of myokines has previously been reviewed (Pedersen et al., 2007; Pedersen, 2009, 2011, 2019; Walsh, 2009; Brandt and Pedersen, 2010; Arnold et al., 2011; Hamrick, 2011; Trayhurn et al., 2011; Pedersen and Febbraio, 2012; Raschke and Eckel, 2013; Pal et al., 2014; Ahima and Park, 2015; Benatti and Pedersen, 2015; Indrakusuma et al., 2015; Schnyder and Handschin, 2015; Whitham and Febbraio, 2016; Hoffmann and Weigert, 2017; Rodriguez et al., 2017; Ruiz-Casado et al., 2017; Diaz et al., 2018; Fiuza-Luces et al., 2018; Coelho-Junior et al., 2019; Das et al., 2019; Eckel, 2019; Garneau and Aguer, 2019; 
Graf and Ferrari, 2019; Lee and Jun, 2019). Until now the biological function has been described for only approximately $5 \%$ of all known myokines. Nonetheless, the identification of the myokinome has provided a new paradigm and a conceptual basis for understanding by which mechanisms muscles communicate with other organs. Several of these myokines relate to immune function and inflammation. Low-grade inflammation is associated with several types of obesity-related diseases such as diabetes, cardiovascular disease, cirrhosis, and cancer. We suggest that control of this pathology-related inflammation can in part be ascribed by the release of immunogenic myokines. These are highlighted in Figure 1.

\section{MUSCLE-IMMUNE-INFLAMMATION CROSSTALK}

Muscle has impact on lymphocyte and neutrophil trafficking and inflammation (Duggal et al., 2019). During exercise, neutrophils as well as natural killer (NK) cells and other lymphocytes enter the blood. Exercise of high intensity and long duration leads to a decline in lymphocyte number, while the concentration of neutrophils increase (McCarthy and Dale, 1988; Pedersen and Hoffman-Goetz, 2000) via mechanisms that include adrenaline and cortisol. IL- 6 has been shown to be involved in mediating the increase in cortisol (Steensberg et al., 2003).

Lack of exercise and obesity are accompanied by low level chronic inflammation (Pedersen et al., 2003b; Petersen and Pedersen, 2005; Pedersen, 2006; Pedersen, 2006, 2017; Benatti and Pedersen, 2015; Knudsen and Pedersen, 2015; Karstoft and Pedersen, 2016). The anti-inflammatory effects of exercise training are induced with each single bout of exercise as well as via training adaptation leading to a decrease in the amount of abdominal fat.

IL-6 increases with exercise and promotes the occurring of two cytokines with anti-inflammatory effects (Steensberg et al., 2003). IL-1 receptor antagonist (IL-1 ra) blocks IL-1 $\beta$ signaling (Dinarello, 1994) and IL-10 prevents TNF- $\alpha$ production (Opp et al., 1995). A study in healthy humans showed that a bout of exercise or administration of IL- 6 before infusion of endotoxin abolished the increase in plasma levels of TNF- $\alpha$ that was seen in a control situation (Starkie et al., 2003). It was concluded that a single bout of exercise mediates an anti-inflammatory signal, which is likely to be partly mediated by IL-6 (Pedersen, 2017).

Exercise can also induce anti-inflammatory effects via a reduction in abdominal fat (Rosenkilde et al., 2016). Abdominal adiposity, reflecting a high amount of visceral fat, is associated with cardiovascular disease, type 2 diabetes, dementia and allcause mortality (Pedersen, 2009). Accumulation of visceral fat represents an important source of origin of chronic systemic inflammation, as it has been shown to be more inflamed than subcutaneous fat, constituting an important source of inflammatory markers (Yudkin, 2007).

Physical inactivity leads to an increased amount of visceral fat and consequently an environment of inflammation, which provokes a network of chronic diseases (Benatti and Pedersen, 2015).
Recent evidence exists that exercise training decreases the amount of visceral and cardiac fat mass (Christensen et al., 2019a,b; Wedell-Neergaard et al., 2019) mediated by musclederived IL-6 (Wedell-Neergaard et al., 2019) as described below.

\section{MUSCLE-ADIPOSE CROSSTALK}

Exercise-induced IL-6 has significant effects on fat metabolism (Pedersen, 2013, 2018). In vivo studies in humans show that rhIL-6 enhances lipolysis and fat oxidation (van Hall et al., 2003; Petersen et al., 2005). Epidemiological studies demonstrate that an association exists between abdominal adiposity and low fitness (Wedell-Neergaard et al., 2018a,b). Intervention studies show that reduced number of daily steps provoke accumulation of visceral adipose tissue (Olsen et al., 2008; Benatti and Pedersen, 2015), whereas exercise training reduced abdominal adiposity (Ross et al., 2000; Nordby et al., 2012). In a recent study, abdominally obese humans were randomized to tocilizumab (IL6 receptor antibody) or placebo during an intervention of 12 weeks with either aerobic exercise or no exercise (Christensen J. F. et al., 2018; Wedell-Neergaard et al., 2019). While exercise training led to a reduction in visceral adipose tissue mass, this effect was completely abolished by IL-6 receptor blockade (Wedell-Neergaard et al., 2019).

It has also been hypothesized that exercise may induce browning of white adipose tissue (Rodriguez et al., 2017; Eckel, 2019; Townsend and Wright, 2019). Myokines with browning properties include irisin (Bostrom et al., 2012), meteorin-like (Rao et al., 2014), and IL-6 (Knudsen et al., 2014). The finding that exercise-induced myokines may induce browning of white adipose tissue has been demonstrated in rodent models, but not consistently so in humans (Norheim et al., 2014; Vosselman et al., 2015; Severinsen et al., 2020).

\section{MUSCLE-CANCER CROSSTALK}

Metabolic syndrome has been tied to risk of several types of cancer (Esposito et al., 2012). The vast amount of epidemiological studies demonstrate that exercise training decreases the risk of cancer and contributes to control disease progression. Exercise has also beneficial impact on anti-cancer therapy and improves physical and mental health in general. Being physically active reduces the risk of approximately 13 different cancer types (Moore et al., 2016; Pedersen et al., 2016; Christensen R. H. et al., 2018; Hojman et al., 2018). Exercise training after a diagnosis of breast cancer, prostate cancer and colorectal cancer are associated with an increased survival rate (Pedersen, 2018).

Given that cancer is associated with low level chronic inflammation, which may contribute to tumor progression, it is possible that the ability of physical training to create an anti-inflammatory environment, may facilitate exercise-induced protection on cancer growth (Hojman et al., 2018).

Pernille Hojman studied exercise effects on tumor growth in rodent models (Pedersen et al., 2016). She established a B16F10 melanoma model and exposed tumor-bearing mice to 


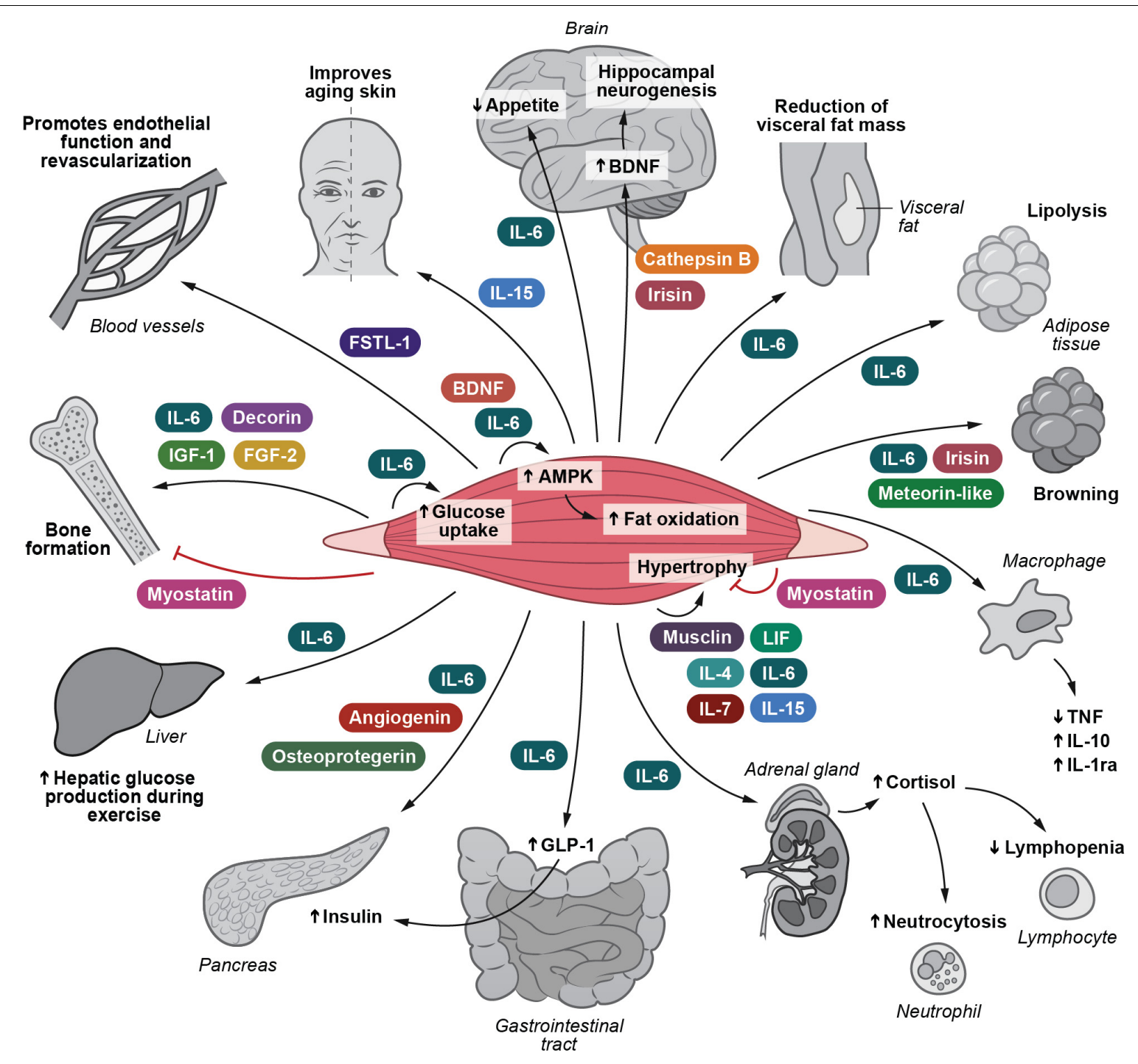

FIGURE 1 | I Irisin and Cathepsin B enhance BDNF production and thereby hippocampal neurogenesis. IL-6 inhibits appetite and stimulates lipolysis. IL-6 also plays a role in decreasing the amount of visceral fat. IL-6, irisin and meteorin-like are involved in turning white adipose tissue into a brown phenotype. IL-15 retards skin aging. IL-6, decorin, FGF-2 and IGF-1 positively influence bone formation. Myostatin negatively influence bone formation. Musclin, LIF, IL-4, IL-6, IL-7, and IL-15 are involved in mediating muscle hypertrophy, whereas myostatin obstructs muscle hypertrophy. IL-6 and BDNF stimulate AMPK activation and hence fat oxidation. IL-6 e stimulates glucose uptake and hepatic glucose output during exercise. IL-6 induces the expression of GLP-1 by the L cells of the intestine leading to enhanced insulin secretion. IL-6 exerts anti-inflammatory effects by inhibiting TNF production and by stimulating IL-1ra and IL-10 production. IL-6 enhances cortisol production, leading to neutrocytosis and lymphopenia. FSTL-1 has beneficial effects on endothelial function and revascularization of atherosclerotic blood vessels.

Osteoprotegerin, angiogenin, and IL-6 possess beta-cell protective actions against inflammatory cytokines. AMPK, 5'-AMP-activated protein kinase; BDNF, brain-derived neurotrophic factor; FGF-2, fibroblast growth factor 2; FGF-21, fibroblast growth factor 21; FSTL-1, follistatin-related protein 1; GLP-1, glucagon-like peptide 1; IGF-1, insulin-like growth factor I; IL-1ra, IL-1 receptor antagonist; LIF, leukemia inhibitory factor; TGF- $\beta$, transforming growth factor $\beta$; TNF, tumor necrosis factor. Adapted with permission from Severinsen and Pedersen (2020).

wheel running or control. It appeared that exercising mice had a significant decrease in tumor mass and incidence.

Myokines are involved in mediating the effect of exercise on tumor growth. When breast cancer cells were treated with irisin, they were more likely to undergo apoptosis (Hojman et al., 2018).

The myokine oncostatin M (Pedersen et al., 2016) was shown to inhibit breast cancer cell proliferation. The myokine, secreted protein acidic and rich in cysteine (SPARC) was shown to reduce tumor in the colon of exercising mice (Aoi et al., 2013).
Exercise also induces acute increases in epinephrine and norepinephrine, which are involved in recruiting NK cells in humans during exercise. Breast cancer cells exposed to serum collected after a single bout of acute exercise and thereafter injected into mice, led to a reduction of tumor formation (Dethlefsen et al., 2017). This effect was, however, completely blunted when we blocked $\beta$-adrenergic signaling, the pathway through which epinephrine and norepinephrine work (Dethlefsen et al., 2017). 


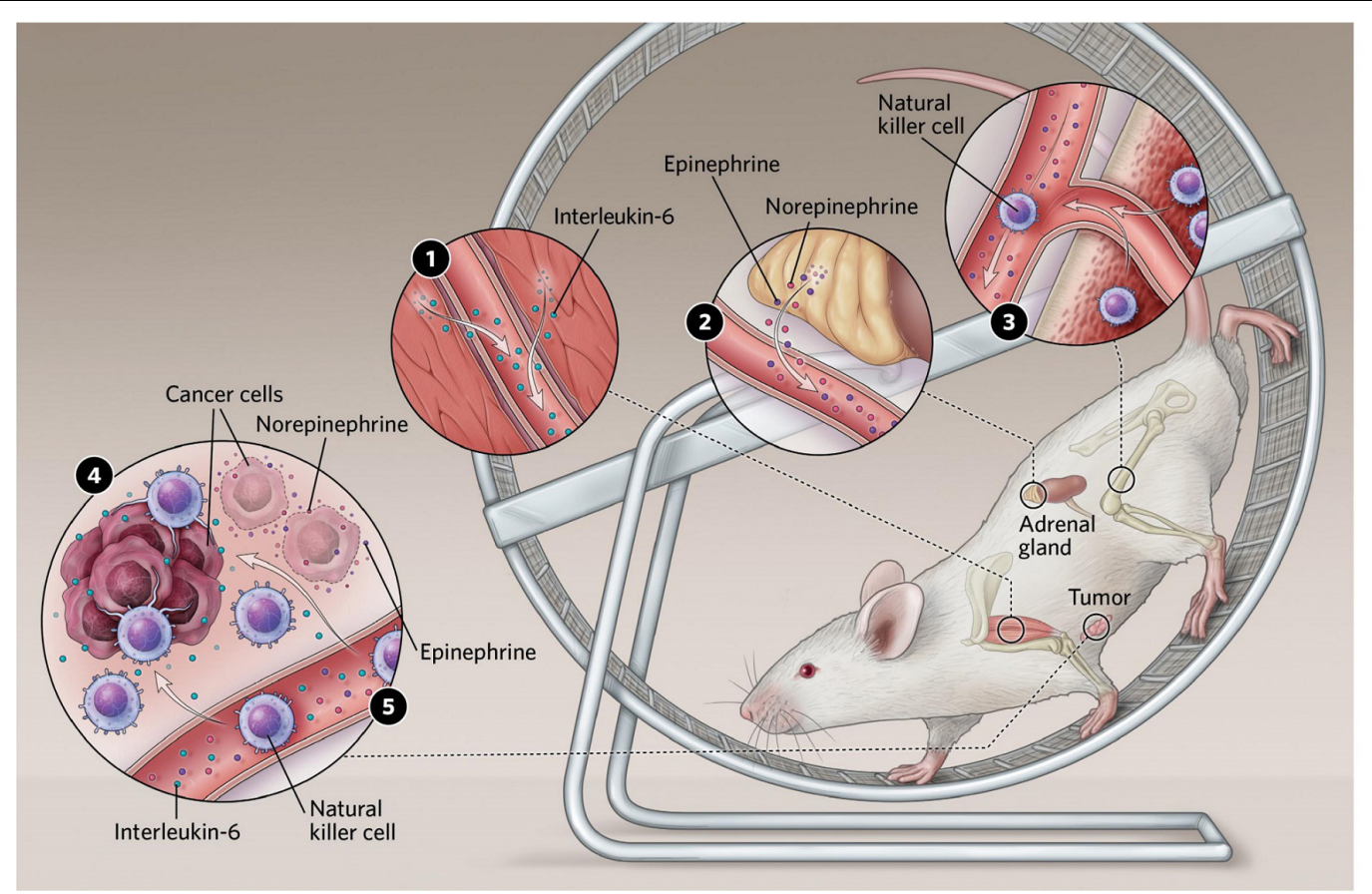

FIGURE 2 | (1) Exercising muscles release multiple compounds known as myokines. Several of these have been shown to affect cancer cell proliferation in culture, and some, including interleukin-6, slow tumor growth in mice. (2) Exercise stimulates an increase in levels of the stress hormones epinephrine and norepinephrine, which can both act directly on tumors and stimulate immune cells to enter the bloodstream. (3) Epinephrine also stimulates natural killer cells to enter circulation. (4) In mice, interleukin-6 appears to direct natural killer cells to home in on tumors. Reprinted with permission from Pedersen (2020). Illustrator: Scott Leighton. (5) Epinephrine and norepinephrine along with some myokines can inhibit tumor growth.

These findings suggested that epinephrine and norepinephrine play a key role in the cancer-inhibiting effects of exercise. To this end, catecholamine release has been linked to the best-characterized myokine, IL-6, which increases exponentially during exercise in humans. Muscle cells from rats have been shown to release IL-6 upon stimulation with epinephrine (Frost et al., 2004), and injection of a high dose of IL-6 in human subjects resulted in increased epinephrine levels (van Hall et al., 2003).

In the cancer-setting, Pernille Hojman and her team found that the inhibitory effects of exercise on tumor growth were mediated via a direct regulation of natural killer (NK) cells, where these were mobilized to the circulation and redistributed to the tumor tissue by a mechanism involving both epinephrine and IL-6. Blocking IL-6 signaling during exercise abolished the exercise-induced inhibition of tumor growth, suggesting that IL6 plays a role in mediating anti-cancer effects (Aoi et al., 2013; Hojman et al., 2011; Hojman et al., 2018; Lucia and Ramirez, 2016; Manole et al., 2018; Figure 2).

In addition to the crucial increase of tumor-infiltrating $\mathrm{NK}$ cells with exercise, microarray analyses of the tumors revealed that $52 \%$ of the upregulated gene ontology pathways were linked to immunological and inflammatory responses, and qPCR analyses showed increased tumoral expression of several cytokines (Pedersen et al., 2016). Amongst these upregulated cytokines were Interferon- $\gamma$, which has been reported to stimulate immunoregulatory molecules on a wide selection of both healthy and diseased cells (Sun et al., 2018), and IL-15 known to stimulate activation and cytotoxicity of both NK cells and T cells (Guo et al., 2017). These clear associations between exercise and the immunogenic profiles of tumors makes it higly relevant to study the possible benefits of combining exercise with immunotherapy. These could either be checkpoint inhibitors or immune-stimulatory treatments.

\section{MUSCLE-CARDIAC TISSUE CROSSTALK}

The inflamed arterial wall is a hallmark in the development of cardiovascular disease. Given that each bout of exercise induces anti-inflammatory effects, mediated by IL-6, it is likely that transient increases in this myokine contributes to the protection against atherosclerotic disease.

Another myokine of importance for cardiac disease is follistatin-like 1 (FSTL1), which is expressed by skeletal as well as cardiac muscle cells (Shimano et al., 2012). FSTL1 promotes the function of endothelial cells and is involved in revascularization (Oshima et al., 2008; Ouchi et al., 2008), although its role in humans need to identified.

\section{MUSCLE-LIVER CROSSTALK}

Exercise stimulates an augmented production of glucose from the liver (Wasserman et al., 1991). In 1961, Goldstein (1961) 
proposed that contracting muscle produced an exercise factor that could stimulate hepatic glucose output. Evidence exists that IL-6 plays a role in hepatic glucose output. This was the conclusion from a study in which young healthy males did $2 \mathrm{~h}$ of cycle ergometer exercise on 3 different days at: (1) a high intensity; (2) a low intensity; and (3) a low intensity + infusion of IL- 6 at a concentration to mimic the systemic increase in IL-6 during exercise of high intensity. The results from this human experiment demonstrated that exercise-induced IL-6 is involved in triggering hepatic glucose output during exercise (Febbraio et al., 2004).

\section{Muscle-Beta-Cell}

Studying human primary muscle cell cultures established from triceps brachii, soleus and quadriceps identified two myokines, angiogenin and osteoprotegerin, which were shown to be triceps specific myokines, mediating anti-inflammatory actions and protecting beta-cell survival (Rutti et al., 2018). Moreover, it has been shown that IL-6 positively regulates $\beta$-cell mass in vivo (Ellingsgaard et al., 2008). The increase in IL-6 with each bout of exercise may be involved in protecting pancreatic $\beta$-cell mass and function.

\section{OTHER MUSCLE-ORGAN CROSS-TALKS}

\section{Muscle-Brain Crosstalk}

Regular exercise has beneficial effects on brain health (Cotman et al., 2007; Mattson, 2012). The fact that exercise is sensed by the brain suggests a direct crosstalk between working muscle and brain function (Pedersen and Febbraio, 2012; Benatti and Pedersen, 2015; Leardini-Tristao et al., 2019; Pedersen, 2019). Studies in humans (Erickson et al., 2011) and rodents (Kobilo et al., 2011) demonstrate a positive effect of exercise on hippocampus volume (Kobilo et al., 2011). In humans, brainderived Neurotic factor (BDNF) Studies in humans demonstrate that $\mathrm{BDNF}$ is released from the brain in relation to exercise (Rasmussen et al., 2009; Seifert et al., 2010) and regular exercise for 3 months leads to an increase in the volume of hippocampus (Pajonk et al., 2010). In rodents, BDNF mRNA and protein increase in response to exercise (Pedersen and Febbraio, 2012; Benatti and Pedersen, 2015; Leardini-Tristao et al., 2019; Pedersen, 2019) and stimulate hippocampus growth (Loprinzi and Frith, 2019) as well as memory and learning (Vaynman et al., 2004a,b). Interesting studies in mice show that the myokines cathepsin-B (Moon et al., 2016) and irisin (Wrann et al., 2013) may be released from muscle to blood during exercise, passing from the blood to the brain and directly provoking an increase in brain BDNF. When IL-6 is centrally applied in mice, it suppresses feeding (Timper et al., 2017). Moreover, a much higher IL-6 concentration applied peripherally reduces the intake of food, suggesting that high systemic IL-6 concentrations may pass from the blood to the brain and regulate appetite. The latter results indicate that IL6 released from muscle during exercise of high intensity and long duration (Febbraio and Pedersen, 2002), may lead to a decrease in appetite.

\section{Muscle-Muscle}

Some myokines can exert their effects on the muscle itself. One of these is IL-6, which can work in both an endocrine and a paracrine manner within the muscle (Pedersen and Febbraio, $2008,2012)$. In a metabolic perspective, studies in humans show that IL-6 is capable of increasing glucose uptake by a mechanism that involves activation of AMPK (Carey et al., 2006). Moreover, IL-6 increases insulin-stimulated glucose uptake in vitro as well as in in vivo in health humans (Carey et al., 2006). Furthermore, IL6 increases fatty acid oxidation via AMPK activation (Kahn et al., 2005; Carey et al., 2006). BDNF is yet another myokine, which stimulates AMPK activation and thereby lipid oxidation. BDNF works in an autocrine or paracrine manner (Matthews et al., 2009). Finally, Musclin is an exercise-induced factor (Nishizawa et al., 2004) that promotes mitochondrial biogenesis in murine muscle (Subbotina et al., 2015).

\section{Muscle-Gut}

IL-6 stimulates glucagon-like peptide-1 (GLP-1) secretion in mice from both pancreatic $\beta$-cells and intestinal L-cells, thereby enhancing insulin secretion. A recent human study from our group (Lang Lehrskov et al., 2018) demonstrates that IL-6 slows down the rate of gastric emptying. Thereby IL-6 indirectly exerts beneficial effects on postprandial glucose (Woerle et al., 2008).

\section{Muscle-Skin}

Studies in exercising mice and humans suggest that musclederived IL-15 contributes to avoid aging of the skin (Crane et al., 2015). The latter study showed that that exercise regulates muscular IL-15 expression via skeletal muscle AMPK.

\section{THE POTENTIAL CLINICAL IMPACT OF MYOKINES IN IMMUNOMETABOLISM}

Myokines have been identified which include effects on e.g., lipid and glucose metabolism, browning of white fat, betacell-function, endothelial cell function and tumor growth. The biological and physiological identification of several myokines has identified these to be useful biomarkers for monitoring the exercise training, which is necessary in order to apply exercise as medicine for patients with specific diseases, such as diabetes, cardiovascular diseases and cancer. The identification of new myokines, playing specific roles in immunometabolism, may lead to new therapeutic targets for lifestyle-related diseases.

\section{CONCLUSION}

During exercise, myokines play a role in regulating immune cell trafficking, inflammation and metabolism. Exercise training thereby represents a strategy to induce a anti-inflammation and improved metabolism, which may contribute to decrease the risk or progression of cancer and type 2 diabetes as well as other chronic disorders. 


\section{AUTHOR CONTRIBUTIONS}

$\mathrm{MB}$ and $\mathrm{BP}$ wrote the manuscript. Both authors contributed to the article and approved the submitted version.

\section{REFERENCES}

Ahima, R. S., and Park, H. K. (2015). Connecting myokines and metabolism. Endocrinol. Metab. 30, 235-245. doi: 10.3803/enm.2015.30.3.235

Aoi, W., Naito, Y., Takagi, T., Tanimura, Y., Takanami, Y., Kawai, Y., et al. (2013). A novel myokine, secreted protein acidic and rich in cysteine (SPARC), suppresses colon tumorigenesis via regular exercise. Gut 62, 882-889. doi: 10.1136/gutjnl2011-300776

Arnold, A. S., Egger, A., and Handschin, C. (2011). PGC-1alpha and myokines in the aging muscle - a mini-review. Gerontology 57, 37-43. doi: 10.1159/ 000281883

Benatti, F. B., and Pedersen, B. K. (2015). Exercise as an anti-inflammatory therapy for rheumatic diseases-myokine regulation. Nat. Rev. Rheumatol. 11, 86-97. doi: 10.1038/nrrheum.2014.193

Bostrom, P., Wu, J., Jedrychowski, M. P., Korde, A., Ye, L., Lo, J. C., et al. (2012). A PGC1-alpha-dependent myokine that drives brown-fat-like development of white fat and thermogenesis. Nature 481, 463-468.

Brandt, C., and Pedersen, B. K. (2010). The role of exercise-induced myokines in muscle homeostasis and the defense against chronic diseases. J. Biomed. Biotechnol. 2010:520258.

Carey, A. L., Steinberg, G. R., Macaulay, S. L., Thomas, W. G., Holmes, A. G., Ramm, G., et al. (2006). Interleukin-6 increases insulin-stimulated glucose disposal in humans and glucose uptake and fatty acid oxidation in vitro via AMP-activated protein kinase. Diabetes 55, 2688-2697. doi: 10.2337/db05-1404

Christensen, J. F., Simonsen, C., and Hojman, P. (2018). Exercise training in cancer control and treatment. Compr. Physiol. 9, 165-205. doi: 10.1002/cphy.c180016

Christensen, R. H., Lehrskov, L. L., Wedell-Neergaard, A. S., Legaard, G. E., RiedLarsen, M., Karstoft, K., et al. (2019a). Aerobic exercise induces cardiac fat loss and alters cardiac muscle mass through an interleukin- 6 receptor-dependent mechanism: cardiac analysis of a double-blind randomized controlled clinical trial in abdominally obese humans. Circulation 140, 1684-1686. doi: 10.1161/ circulationaha.119.042287

Christensen, R. H., Wedell-Neergaard, A. S., Lehrskov, L. L., Legaard, G. E., Dorph, E., Larsen, M. K., et al. (2019b). Effect of aerobic and resistance exercise on cardiac adipose tissues: secondary analyses from a randomized clinical trial. JAMA Cardiol. 4, 778-787. doi: 10.1001/jamacardio.2019.2074

Christensen, R. H., Wedell-Neergaard, A. S., Lehrskov, L. L., Legard, G. E., Dorph, E. B., Nymand, S., et al. (2018). The role of exercise combined with tocilizumab in visceral and epicardial adipose tissue and gastric emptying rate in abdominally obese participants: protocol for a randomised controlled trial. Trials 19:266.

Coelho-Junior, H. J., Picca, A., Calvani, R., Uchida, M. C., and Marzetti, E. (2019). If my muscle could talk: Myokines as a biomarker of frailty. Exp. Gerontol. 127:110715. doi: 10.1016/j.exger.2019.110715

Cotman, C. W., Berchtold, N. C., and Christie, L. A. (2007). Exercise builds brain health: key roles of growth factor cascades and inflammation. Trends Neurosci. 30, 464-472. doi: 10.1016/j.tins.2007.06.011

Crane, J. D., MacNeil, L. G., Lally, J. S., Ford, R. J., Bujak, A. L., Brar, I. K., et al. (2015). Exercise-stimulated interleukin-15 is controlled by AMPK and regulates skin metabolism and aging. Aging Cell 14, 625-634. doi: 10.1111/acel.12341

Das, D. K., Graham, Z. A., and Cardozo, C. P. (2019). Myokines in skeletal muscle physiology and metabolism: recent advances and future perspectives. Acta Physiol. 228:e13367.

Dethlefsen, C., Hansen, L. S., Lillelund, C., Andersen, C., Gehl, J., Christensen, J. F., et al. (2017). Exercise-Induced catecholamines activate the hippo tumor suppressor pathway to reduce risks of breast cancer development. Cancer Res. 77, 4894-4904. doi: 10.1158/0008-5472.can-16-3125

Diaz, B. B., Gonzalez, D. A., Gannar, F., Perez, M. C. R., and de Leon, A. C. (2018). Myokines, physical activity, insulin resistance and autoimmune diseases. Immunol. Lett. 203, 1-5. doi: 10.1016/j.imlet.2018.09.002

\section{FUNDING}

The Centre for Physical Activity Research (CFAS) is supported by a grant from TrygFonden.

Dinarello, C. A. (1994). The interleukin-1 family: 10 years of discovery. FASEB J. 8, 1314-1325. doi: 10.1096/fasebj.8.15.8001745

Duggal, N. A., Niemiro, G., Harridge, S. D. R., Simpson, R. J., and Lord, J. M. (2019). Can physical activity ameliorate immunosenescence and thereby reduce age-related multi-morbidity? Nat. Rev. Immunol. 19, 563-572. doi: 10.1038/ s41577-019-0177-9

Eckel, J. (2019). Myokines in metabolic homeostasis and diabetes. Diabetologia 62, 1523-1528. doi: 10.1007/s00125-019-4927-9

Ellingsgaard, H., Ehses, J. A., Hammar, E. B., Van, L. L., Quintens, R., Martens, G., et al. (2008). Interleukin-6 regulates pancreatic alpha-cell mass expansion. Proc. Natl. Acad. Sci. U.S.A. 105, 13163-13168. doi: 10.1073/pnas.0801059105

Erickson, K. I., Voss, M. W., Prakash, R. S., Basak, C., Szabo, A., Chaddock, L., et al. (2011). Exercise training increases size of hippocampus and improves memory. Proc. Natl. Acad. Sci. U.S.A. 108, 3017-3022. doi: 10.1073/pnas.101595 0108

Esposito, K., Chiodini, P., Colao, A., Lenzi, A., and Giugliano, D. (2012). Metabolic syndrome and risk of cancer: a systematic review and meta-analysis. Diabetes Care 35, 2402-2411.

Febbraio, M. A., Hiscock, N., Sacchetti, M., Fischer, C. P., and Pedersen, B. K. (2004). Interleukin-6 is a novel factor mediating glucose homeostasis during skeletal muscle contraction. Diabetes 53, 1643-1648. doi: 10.2337/diabetes.53. 7.1643

Febbraio, M. A., and Pedersen, B. K. (2002). Muscle-derived interleukin-6: mechanisms for activation and possible biological roles. FASEB J. 16, 13351347. doi: 10.1096/fj.01-0876rev

Fiuza-Luces, C., Santos-Lozano, A., Joyner, M., Carrera-Bastos, P., Picazo, O., Zugaza, J. L., et al. (2018). Exercise benefits in cardiovascular disease: beyond attenuation of traditional risk factors. Nat. Rev. Cardiol. 15, 731-743. doi: 10.1038/s41569-018-0065-1

Frost, R. A., Nystrom, G. J., and Lang, C. H. (2004). Epinephrine stimulates IL-6 expression in skeletal muscle and C2C12 myoblasts: role of c-Jun NH2-terminal kinase and histone deacetylase activity. Am. J. Physiol. Endocrinol. Metab. 286, E809-E817.

Garneau, L., and Aguer, C. (2019). Role of myokines in the development of skeletal muscle insulin resistance and related metabolic defects in type 2 diabetes. Diabetes Metab. 45, 505-516. doi: 10.1016/j.diabet.2019.02.006

Goldstein, M. (1961). Humoral nature of hypoglycemia in muscular activity. Am. J. Physiol. 200, 67-70. doi: 10.1152/ajplegacy.1961.200.1.67

Graf, C., and Ferrari, N. (2019). Metabolic health-the role of Adipo-Myokines. Int. J. Mol. Sci. 20:6159. doi: 10.3390/ijms20246159

Guo, Y., Luan, L., Patil, N. K., and Sherwood, E. R. (2017). Immunobiology of the IL-15/IL-15R $\alpha$ complex as an antitumor and antiviral agent. Cytokine Growth Factor Rev. 38, 10-21. doi: 10.1016/j.cytogfr.2017.08.002

Hamrick, M. W. (2011). A role for myokines in muscle-bone interactions. Exerc. Sport Sci. Rev. 39, 43-47. doi: 10.1097/jes.0b013e318201f601

Hoffmann, C., and Weigert, C. (2017). Skeletal muscle as an endocrine organ: the role of myokines in exercise adaptations. Cold Spring Harb. Perspect. Med. 1:a029793. doi: 10.1101/cshperspect.a029793

Hojman, P., Dethlefsen, C., Brandt, C., Hansen, J., Pedersen, L., and Pedersen, B. K. (2011). Exercise-induced muscle-derived cytokines inhibit mammary cancer cell growth. Am. J. Physiol. Endocrinol. Metab. 301, E504-E510.

Hojman, P., Gehl, J., Christensen, J. F., and Pedersen, B. K. (2018). Molecular mechanisms linking exercise to cancer prevention and treatment. Cell Metab. 27, 10-21. doi: 10.1016/j.cmet.2017.09.015

Indrakusuma, I., Sell, H., and Eckel, J. (2015). Novel mediators of adipose tissue and muscle crosstalk. Curr. Obes. Rep. 4, 411-417. doi: 10.1007/s13679-0150174-7

Kahn, B. B., Alquier, T., Carling, D., and Hardie, D. G. (2005). AMP-activated protein kinase: ancient energy gauge provides clues to modern understanding of metabolism. Cell Metab. 1, 15-25. doi: 10.1016/j.cmet.2004.12.003 
Karstoft, K., and Pedersen, B. K. (2016). Exercise and type 2 diabetes: focus on metabolism and inflammation. Immunol. Cell Biol. 94, 146-150. doi: 10.1038/ icb. 2015.101

Khan, S. U., and Ghafoor, S. (2019). Myokines: discovery challenges and therapeutic impediments. J. Pak. Med. Assoc. 69, 1014-1017.

Knudsen, J. G., Murholm, M., Carey, A. L., Bienso, R. S., Basse, A. L., Allen, T. L., et al. (2014). Role of IL-6 in exercise training- and cold-induced UCP1 expression in subcutaneous white adipose tissue. PLoS One 9:e84910. doi: 10. 1371/journal.pone.0084910

Knudsen, S. H., and Pedersen, B. K. (2015). Targeting inflammation through a physical active lifestyle and pharmaceuticals for the treatment of type 2 diabetes. Curr. Diab Rep. 15:82.

Kobilo, T., Liu, Q. R., Gandhi, K., Mughal, M., Shaham, Y., and van Praag, H. (2011). Running is the neurogenic and neurotrophic stimulus in environmental enrichment. Learn. Mem. 18, 605-609.

Lang Lehrskov, L., Lyngbaek, M. P., Soederlund, L., Legaard, G. E., Ehses, J. A., Heywood, S. E., et al. (2018). Interleukin-6 delays gastric emptying in humans with direct effects on glycemic control. Cell Metab. 27, 1201-1211.

Leardini-Tristao, M., Charles, A. L., Lejay, A., Pizzimenti, M., Meyer, A., Estato, V., et al. (2019). Beneficial effect of exercise on cognitive function during peripheral arterial disease: potential involvement of Myokines and microglial anti-inflammatory phenotype enhancement. J. Clin. Med. 8:653.

Lee, J. H., and Jun, H. S. (2019). Role of myokines in regulating skeletal muscle mass and function. Front. Physiol. 10:42. doi: 10.3389/fphys.2019.00042

Loprinzi, P. D., and Frith, E. (2019). A brief primer on the mediational role of BDNF in the exercise-memory link. Clin. Physiol. Funct. Imaging 39, 9-14.

Lucia, A., and Ramirez, M. (2016). Muscling in on cancer. N. Engl. J. Med. 375, 892-894.

Manole, E., Ceafalan, L. C., Popescu, B. O., Dumitru, C., and Bastian, A. E. (2018). Myokines as possible therapeutic targets in cancer Cachexia. J. Immunol. Res. 2018:8260742.

Mathis, D., and Shoelson, S. E. (2011). Immunometabolism: an emerging frontier. Nat. Rev. Immunol. 11:81.

Matthews, V. B., Astrom, M. B., Chan, M. H., Bruce, C. R., Krabbe, K. S., Prelovsek, O., et al. (2009). Brain-derived neurotrophic factor is produced by skeletal muscle cells in response to contraction and enhances fat oxidation via activation of AMP-activated protein kinase. Diabetologia 52, 1409-1418.

Mattson, M. P. (2012). Energy intake and exercise as determinants of brain health and vulnerability to injury and disease. Cell Metab. 16, 706-722.

McCarthy, D. A., and Dale, M. M. (1988). The leucocytosis of exercise. A review and model. Sports Med. 6, 333-363.

Moon, H. Y., Becke, A., Berron, D., Becker, B., Sah, N., Benoni, G., et al. (2016). Running-induced systemic cathepsin b secretion is associated with memory function. Cell Metab. 24, 332-340.

Moore, S. C., Lee, I. M., Weiderpass, E., Campbell, P. T., Sampson, J. N., Kitahara, C. M., et al. (2016). Association of leisure-time physical activity with risk of 26 types of cancer in 1.44 million adults. JAMA Intern. Med. 176, 816-825.

Nishizawa, H., Matsuda, M., Yamada, Y., Kawai, K., Suzuki, E., Makishima, M., et al. (2004). Musclin, a novel skeletal muscle-derived secretory factor. J. Biol. Chem. 279, 19391-19395.

Nordby, P., Auerbach, P. L., Rosenkilde, M., Kristiansen, L., Thomasen, J. R., Rygaard, L., et al. (2012). Endurance training per se increases metabolic health in young, moderately overweight men. Obesity 20, 2202-2212.

Norheim, F., Langleite, T. M., Hjorth, M., Holen, T., Kielland, A., Stadheim, H. K., et al. (2014). The effects of acute and chronic exercise on PGC-1alpha, irisin and browning of subcutaneous adipose tissue in humans. FEBS J. 281, 739-749.

Olsen, R. H., Krogh-Madsen, R., Thomsen, C., Booth, F. W., and Pedersen, B. K. (2008). Metabolic responses to reduced daily steps in healthy nonexercising men. JAMA 299, 1261-1263.

Opp, M. R., Smith, E. M., and Hughes, T. K. Jr. (1995). Interleukin-10 (cytokine synthesis inhibitory factor) acts in the central nervous system of rats to reduce sleep. J. Neuroimmunol. 60, 165-168.

Oshima, Y., Ouchi, N., Sato, K., Izumiya, Y., Pimentel, D. R., and Walsh, K. (2008). Follistatin-like 1 is an Akt-regulated cardioprotective factor that is secreted by the heart. Circulation 117, 3099-3108.

Ouchi, N., Oshima, Y., Ohashi, K., Higuchi, A., Ikegami, C., Izumiya, Y., et al. (2008). Follistatin-like 1, a secreted muscle protein, promotes endothelial cell function and revascularization in ischemic tissue through a nitric-oxide synthase-dependent mechanism. J. Biol. Chem. 283, 32802-32811.

Pajonk, F. G., Wobrock, T., Gruber, O., Scherk, H., Berner, D., Kaizl, I., et al. (2010). Hippocampal plasticity in response to exercise in schizophrenia. Arch. Gen. Psychiatry 67, 133-143.

Pal, M., Febbraio, M. A., and Whitham, M. (2014). From cytokine to myokine: the emerging role of interleukin-6 in metabolic regulation. Immunol. Cell Biol. 92, 331-339.

Pedersen, B. K. (2006). The anti-inflammatory effect of exercise: its role in diabetes and cardiovascular disease control. Essays Biochem. 42, 105-117.

Pedersen, B. K. (2009). The Diseasome of Physical Inactivity- and the role of myokines in muscle-fat cross talk. J. Physiol. 587, 5559-5568.

Pedersen, B. K. (2011). Exercise-induced myokines and their role in chronic diseases. Brain Behav. Immun. 25, 811-816.

Pedersen, B. K. (2013). Muscle as a secretory organ. Compr. Physiol. 3, 1337-1362.

Pedersen, B. K. (2017). Anti-inflammatory effects of exercise: role in diabetes and cardiovascular disease. Eur. J. Clin. Invest. 47, 600-611.

Pedersen, B. K. (2018). The physiology of optimizing health with a focus on exercise as medicine. Annu. Rev. Physiol. 81, 607-627.

Pedersen, B. K. (2019). Physical activity and muscle-brain crosstalk. Nat. Rev. Endocrinol. 15, 383-392.

Pedersen, B. K. (2020). Regular exercise helps patients combat cancer. Scientist.

Pedersen, B. K., Akerstrom, T. C., Nielsen, A. R., and Fischer, C. P. (2007). Role of myokines in exercise and metabolism. J. Appl. Physiol. 103, 1093-1098.

Pedersen, B. K., and Febbraio, M. A. (2008). Muscle as an endocrine organ: focus on muscle-derived interleukin-6. Physiol. Rev. 88, 1379-1406.

Pedersen, B. K., and Febbraio, M. A. (2012). Muscles, exercise and obesity: skeletal muscle as a secretory organ. Nat. Rev. Endocrinol. 8, 457-465.

Pedersen, B. K., and Hoffman-Goetz, L. (2000). Exercise and the immune system: regulation, integration and adaptation. Physiol. Rev. 80, 1055-1081.

Pedersen, B. K., Steensberg, A., Fischer, C., Keller, C., Keller, P., Plomgaard, P., et al. (2003a). Searching for the exercise factor: Is IL-6 a candidate? J. Muscle Res. Cell Motil. 24, 113-119.

Pedersen, B. K., Steensberg, A., Keller, P., Keller, C., Fischer, C., Hiscock, N., et al. (2003b). Muscle-derived interleukin-6: lipolytic, anti-inflammatory and immune regulatory effects. Pflugers Arch. Eur. J. Physiol. 446, 9-16.

Pedersen, L., Idorn, M., Olofsson, G. H., Lauenborg, B., Nookaew, I., Hansen, R. H., et al. (2016). Voluntary running suppresses tumor growth through epinephrineand IL-6-dependent NK cell mobilization and redistribution. Cell Metab. 23, 554-562.

Petersen, A. M., and Pedersen, B. K. (2005). The anti-inflammatory effect of exercise. J. Appl. Physiol. 98, 1154-1162.

Petersen, A. M., and Pedersen, B. K. (2006). The role of IL-6 in mediating the anti-inflammatory effects of exercise. J. Physiol. Pharmacol. 57(Suppl. 10), 43-51.

Petersen, E. W., Carey, A. L., Sacchetti, M., Steinberg, G. R., Macaulay, S. L., Febbraio, M. A., et al. (2005). Acute IL-6 treatment increases fatty acid turnover in elderly humans in vivo and in tissue culture in vitro: evidence that IL-6 acts independently of lipolytic hormones. Am. J. Physiol. 288, E155-E162.

Rao, R. R., Long, J. Z., White, J. P., Svensson, K. J., Lou, J., Lokurkar, I., et al. (2014). Meteorin-like is a hormone that regulates immune-adipose interactions to increase beige fat thermogenesis. Cell 157, 1279-1291.

Raschke, S., and Eckel, J. (2013). Adipo-myokines: two sides of the same coinmediators of inflammation and mediators of exercise. Mediators Inflamm. 2013:320724

Rasmussen, P., Brassard, P., Adser, H., Pedersen, M. V., Leick, L., Hart, E., et al. (2009). Evidence for a release of brain-derived neurotrophic factor from the brain during exercise. Exp. Physiol. 94, 1062-1069.

Rodriguez, A., Becerril, S., Ezquerro, S., Mendez-Gimenez, L., and Fruhbeck, G. (2017). Crosstalk between adipokines and myokines in fat browning. Acta Physiol. 219, 362-381.

Rosenkilde, M., Nordby, P., and Stallknecht, B. (2016). Maintenance of improvements in fitness and fatness 1 year after a 3-month lifestyle intervention in overweight men. Eur. J. Clin. Nutr. 70, 1212-1214.

Ross, R., Dagnone, D., Jones, P. J., Smith, H., Paddags, A., Hudson, R., et al. (2000). Reduction in obesity and related comorbid conditions after diet-induced weight 
loss or exercise-induced weight loss in men. A randomized, controlled trial. Ann. Intern. Med. 133, 92-103.

Ruiz-Casado, A., Martín-Ruiz, A., Pérez, L. M., Provencio, M., Fiuza-Luces, C., and Lucia, A. (2017). Exercise and the Hallmarks of Cancer. Trends Cancer 3, 423-441.

Rutti, S., Dusaulcy, R., Hansen, J. S., Howald, C., Dermitzakis, E. T., Pedersen, B. K., et al. (2018). Angiogenin and Osteoprotegerin are type II muscle specific myokines protecting pancreatic beta-cells against proinflammatory cytokines. Sci. Rep. 8:10072.

Schnyder, S., and Handschin, C. (2015). Skeletal muscle as an endocrine organ: PGC-1alpha, myokines and exercise. Bone 80, 115-125.

Seifert, T., Brassard, P., Wissenberg, M., Rasmussen, P., Nordby, P., Stallknecht, B., et al. (2010). Endurance training enhances BDNF release from the human brain. Am. J. Physiol. Regul. Integr. Comp. Physiol. 298, R372-R377.

Severinsen, M. C. K., and Pedersen, B. K. (2020). Muscle-organ crosstalk: the emerging roles of myokines. Endocr. Rev. 41, 594-609.

Severinsen, M. C. K., Schéele, C., and Pedersen, B. K. (2020). Exercise and browning of white adipose tissue - a translational perspective. Curr. Opin. Pharmacol. 52, 18-24.

Shimano, M., Ouchi, N., and Walsh, K. (2012). Cardiokines: recent progress in elucidating the cardiac secretome. Circulation 126, e327-e332.

Starkie, R., Ostrowski, S. R., Jauffred, S., Febbraio, M., and Pedersen, B. K. (2003). Exercise and IL-6 infusion inhibit endotoxin-induced TNF-alpha production in humans. FASEB J. 17, 884-886.

Steensberg, A., Fischer, C. P., Keller, C., Moller, K., and Pedersen, B. K. (2003). IL-6 enhances plasma IL-1ra, IL-10, and cortisol in humans. Am. J. Physiol. Endocrinol. Metab. 285, E433-E437.

Subbotina, E., Sierra, A., Zhu, Z., Gao, Z., Koganti, S. R., Reyes, S., et al. (2015). Musclin is an activity-stimulated myokine that enhances physical endurance. Proc. Natl. Acad. Sci. U.S.A. 112, 16042-16047.

Sun, C., Mezzadra, R., and Schumacher, T. N. (2018). Regulation and Function of the PD-L1 Checkpoint. Immunity 48, 434-452.

Timper, K., Denson, J. L., Steculorum, S. M., Heilinger, C., Engstrom-Ruud, L., Wunderlich, C. M., et al. (2017). IL-6 improves energy and glucose homeostasis in obesity via enhanced central IL-6 trans-signaling. Cell Rep. 19, 267-280.

Townsend, L. K., and Wright, D. C. (2019). Looking on the "brite" side exerciseinduced browning of white adipose tissue. Pflugers Arch. 471, 455-465.

Trayhurn, P., Drevon, C. A., and Eckel, J. (2011). Secreted proteins from adipose tissue and skeletal muscle - adipokines, myokines and adipose/muscle crosstalk. Arch Physiol. Biochem. 117, 47-56.

van Hall, G., Steensberg, A., Sacchetti, M., Fischer, C., Keller, C., Schjerling, P., et al. (2003). Interleukin-6 stimulates lipolysis and fat oxidation in humans. J. Clin. Endocrinol. Metab. 88, 3005-3010.

Vaynman, S., Ying, Z., and Gomez-Pinilla, F. (2004a). Exercise induces BDNF and synapsin I to specific hippocampal subfields. J. Neurosci. Res. 76, 356-362.
Vaynman, S., Ying, Z., and Gomez-Pinilla, F. (2004b). Hippocampal BDNF mediates the efficacy of exercise on synaptic plasticity and cognition. Eur. J. Neurosci. 20, 2580-2590.

Vosselman, M. J., Hoeks, J., Brans, B., Pallubinsky, H., Nascimento, E. B., van der Lans, A. A., et al. (2015). Low brown adipose tissue activity in endurancetrained compared with lean sedentary men. Int. J. Obes. 39, 1696-1702.

Walsh, K. (2009). Adipokines, myokines and cardiovascular disease. Circ. J. 73, $13-18$.

Wasserman, D. H., Lacy, D. B., Colburn, C. A., Bracy, D., and Cherrington, A. D. (1991). Efficiency of compensation for absence of fall in insulin during exercise. Am. J. Physiol. 261(5 Pt 1), E587-E597.

Wedell-Neergaard, A. S., Eriksen, L., Grønbæk, M., Pedersen, B. K., KroghMadsen, R., and Tolstrup, J. (2018a). Low fitness is associated with abdominal adiposity and low-grade inflammation independent of BMI. PLoS One 13:e0190645. doi: 10.1371/journal.pone.0190645

Wedell-Neergaard, A. S., Krogh-Madsen, R., Petersen, G. L., Hansen, A. M., Pedersen, B. K., Lund, R., et al. (2018b). Cardiorespiratory fitness and the metabolic syndrome: roles of inflammation and abdominal obesity. PLoS One 13:e0194991. doi: 10.1371/journal.pone.0194991

Wedell-Neergaard, A. S., Lang Lehrskov, L., Christensen, R. H., Legaard, G. E., Dorph, E., Larsen, M. K., et al. (2019). Exercise-induced changes in visceral adipose tissue mass are regulated by IL- 6 signaling: a randomized controlled trial. Cell Metab. 29, 844-855.

Whitham, M., and Febbraio, M. A. (2016). The ever-expanding myokinome: discovery challenges and therapeutic implications. Nat. Rev. Drug Discov. 15, 719-729.

Woerle, H. J., Albrecht, M., Linke, R., Zschau, S., Neumann, C., Nicolaus, M., et al. (2008). Importance of changes in gastric emptying for postprandial plasma glucose fluxes in healthy humans. Am. J. Physiol. Endocrinol. Metab. 294, E103-E109.

Wrann, C. D., White, J. P., Salogiannnis, J., Laznik-Bogoslavski, D., Wu, J., Ma, D., et al. (2013). Exercise induces hippocampal BDNF through a PGC1alpha/FNDC5 pathway. Cell Metab. 18, 649-659.

Yudkin, J. S. (2007). Inflammation, obesity, and the metabolic syndrome. Horm. Metab. Res. 39, 707-709.

Conflict of Interest: The authors declare that the research was conducted in the absence of any commercial or financial relationships that could be construed as a potential conflict of interest.

Copyright (c) 2020 Bay and Pedersen. This is an open-access article distributed under the terms of the Creative Commons Attribution License (CC BY). The use, distribution or reproduction in other forums is permitted, provided the original author(s) and the copyright owner(s) are credited and that the original publication in this journal is cited, in accordance with accepted academic practice. No use, distribution or reproduction is permitted which does not comply with these terms. 